\title{
Análise multitemporal do desmatamento nos municípios de Canindé de São Francisco e Poço Redondo, SE
}

\author{
Daniela Pinheiro Bitencurti1 ${ }^{*}$ \\ Felippe Pessoa de Melo \\ Douglas Vieira Gois* \\ Juan Ruiz-Esparza* \\ Adauto de Souza Ribeiro \\ Stephen Francis Ferrari \\ Rosemeri Melo e Souza ${ }^{* * * * * * *}$
}

\section{Resumo}

O processo de desmatamento e o consequente aumento das áreas de pastagens configuram um dos graves processos de degradação das terras na atualidade. A presente pesquisa objetivou realizar análises multitemporais da cobertura vegetal (1980, 1990 e 2000) nos municípios de Canindé de São Francisco e Poço Redondo, com destaque para o Monumento Natural (MONA) Grota do Angico. Foram mapeadas seis classes: Caatinga arbórea, Caatinga arbóreaarbustiva, Caatinga arbustiva, Pasto, Hidrografia e Nuvens. O resultado mostrou o decréscimo das classes de Caatinga, como a variação da Caatinga arbórea entre o anos de 1980, 1990 e 2000 que corresponderam as porcentagens de $6,12,0,71$ e 2,81

\footnotetext{
* Pós-doutoranda no Programa de Desenvolvimento e Meio Ambiente da UFS (danibitencurti@yahoo.com.br).

** Doutor em Geografia pelo PPGE0-UFS (felippemelo@hotmail.com).

**** Doutorando em Geografia pelo PPGEO-UFS (douglasgeograf@hotmail.com).

***** Pós-doutorando em Ecologia, UFS (juancolorado21@hotmail.com).

****** Prof. Dr. Do Departamento de Ecologia da UFS (adauto.ribeiro@pq.cnpq.br).

****** Prof. Dr. Do Departamento de Ecologia da UFS (godbufu@yahoo.co.uk). Prof. $^{a}$ Dr$^{\mathrm{a}}$. do Departamento de Engenharia Ambiental da UFS, GEOPLAN (rome@ufs.br).
}

Geosul, Florianópolis, v. 32, n. 63, p 117-137, jan./abr. 2017 
BITENCOURT, D.P et all. Análise multitemporal do desmatamento nos...

respectivamente. Enquanto houve o consequente aumento da classe de pasto entre as referidas décadas, com 38,46, 52,33 e 69,65 respectivamente. A mesma lógica foi constatada dentro do MONA Grota do Angico.

Palavras-chave: Caatinga; Cobertura vegetal; Classificação.

Multitemporal analysis of deforestation in the municipalities of Canindé de São Francisco and Poço Redondo, SE

\section{Abstract}

The process of deforestation and the resulting increase in grazing areas constitute a serious land degradation process at present time. This research aimed to carry out multitemporals analysis of vegetation cover (1980, 1990 and 2000) in the municipalities of Canindé de São Francisco and Poço Redondo, with emphasis on the Natural Monument (MONA) Grota do Angico. Six classes of vegetation cover were mapped: arboreal Caatinga, arborealshrubby tree Caatinga, shrubby Savanna, pasture, hydrography and clouds. The result showed the decrease of the Caatinga, as arboreal Caatinga variation between the years 1980, 1990 and 2000 that matched the percentages of 6.12 , and 0.712 .81 respectively. While there was a consequent increase in the class of pasture between the referred decades, with percentages of 38,46, 52,33 and 69,65 respectively. The same logic was established within the MONA Grota of Angico.

Key words: Caatinga; Vegetation cover; Classification.

\section{Introdução}

A utilização insustentável e supressão da Caatinga brasileira tem comprometido a biodiversidade deste bioma. O uso da lenha como uma das principais matrizes energéticas e o manejo 
BITENCOURT, D.P et all. Análise multitemporal do desmatamento nos...

inadequado da cobertura vegetal são os principais vetores desse processo degradacional. O mapeamento da cobertura vegetal é um insumo científico essencial para avaliar a evolução da paisagem no tempo e no espaço (COUTURIER, 2011).

A importância dos trabalhos que utilizam a análise multitemporal cresce cada dia mais, considerando as características espectrais das imagens de satélite. Os mapas de desmatamento gerados por imagens de satélite têm sido usados por órgãos do meio ambiente estaduais e federais no combate ao desmatamento (Brandão \& Souza, 2006).

Dentre as técnicas de geoprocessamento disponíveis nos Sistemas de Informação Geográfica (SIGs), o processo de classificação de imagens de satélite, se tornou desde os anos 1990, uma base de produção cartográfica que demonstrou ser altamente eficaz em escala regional por suas qualidades sinóticas (Green \& Hartley, 2000).

Outra ferramenta fundamental para o monitoramento ambiental é o sensoriamento remoto (Moreira, 2011). Esta tecnologia vem sendo aplicada em diversas áreas do conhecimento, devido principalmente, à possibilidade de se obter uma grande quantidade de informações a respeito de uma área ou ecossistema, em intervalos de tempo, com baixo custo (comparando aos métodos tradicionais de amostragens de dados em campo), e boa qualidade, permitindo uma visão integrada do ambiente, entre outras vantagens (Novo, 2011).

Neste trabalho, utilizaremos a análise multitemporal, que é a manipulação de imagens de satélite de uma mesma área em datas diferentes. A área de estudo compreende os municípios de Canindé de São Francisco e Poço Redondo, que abrangem um área natural protegida com alto valor biológico e cultural para o país, o Monumento Natural Grota do Angico.

O Monumento Natural (MONA) da Grota do Angico está localizado entre as coordenadas geográficas $06^{\circ} 45^{\prime}$ ' $00^{\prime} \mathrm{S}$ $89^{\circ} 052^{\prime}$ ' 50', no extremo oeste do Estado de Sergipe, pertence à Mesorregião do Sertão Sergipano e Microrregião do Sertão do São 
BITENCOURT, D.P et all. Análise multitemporal do desmatamento nos...

Francisco, abrangendo partes dos municípios de Poço Redondo e Canindé do São Francisco e sendo margeado ao norte pelo rio São Francisco (SEMARH, 2011).

A Unidade de Conservação MONA Grota do Angico foi criada pelo Governo Estadual de Sergipe, pela SEMARH, tendo o objetivo de preservar o sítio natural da Grota do Angico e elementos culturais associados, mantendo a integridade dos ecossistemas naturais da Caatinga.

A região estudada é compreendida em totalidade pelo bioma Caatinga. A Caatinga é um ecossistema muito importante do ponto de vista biológico por apresentar fauna e flora únicas, formada por uma vasta biodiversidade, rica em recursos genéticos e de vegetação constituída por espécies, lenhosas, herbáceas, cactáceas e bromeliáceas (SISCOM/IBAMA, 2011). A conservação da biodiversidade da Caatinga é um dos maiores desafios da ciência brasileira, pois, além de ter poucos estudos e ser pouco protegida, está rapidamente sendo modificada. Quanto mais informações organizadas e disponíveis sobre as espécies, melhor podem sem traçadas estratégias para a conservação (Associação Caatinga, 2012).

A utilização das imagens de satélite tem um papel fundamental na geração de informações para a sociedade sobre a localização, extensão, intensidade, taxa e frequência temporal do desmatamento e da degradação florestal. Estas informações permitem que políticas e ações de comando e controle surjam para diminuir as consequências dos impactos negativos da ocupação e desenvolvimento nas florestas (Martins Souza Filho et al., 2006). As aplicações na área de conservação e proteção incluem o monitoramento e fiscalização de Áreas Naturais Protegidas, Unidades de Conservação (UCs), Áreas Prioritárias, e demais áreas de interesse da comunidade em geral. O processamento das imagens de satélite também proporciona o fornecimento de informações importantes, como áreas de risco, permitindo aos governos federal e estaduais adiantarem os processos para a criação de novas Unidades de Conservação. 
BITENCOURT, D.P et all. Análise multitemporal do desmatamento nos...

Através dos resultados das classificações das imagens, tentaremos identificar os fatores que possam esclarecer os padrões atuais da paisagem e subsidiar o desenvolvimento de estratégias efetivas de conservação e manejo da Caatinga sergipana.

\section{Materiais e métodos}

\section{Área de estudo}

A área de estudo compreende os municípios de Canindé de São Francisco e Poço Redondo localizados no estado de Sergipe (Figura 1). Esta área foi selecionada devido a região ser de grande importância para o estado, compreendendo a barragem de Xingó e o MONA Grota do Angico.
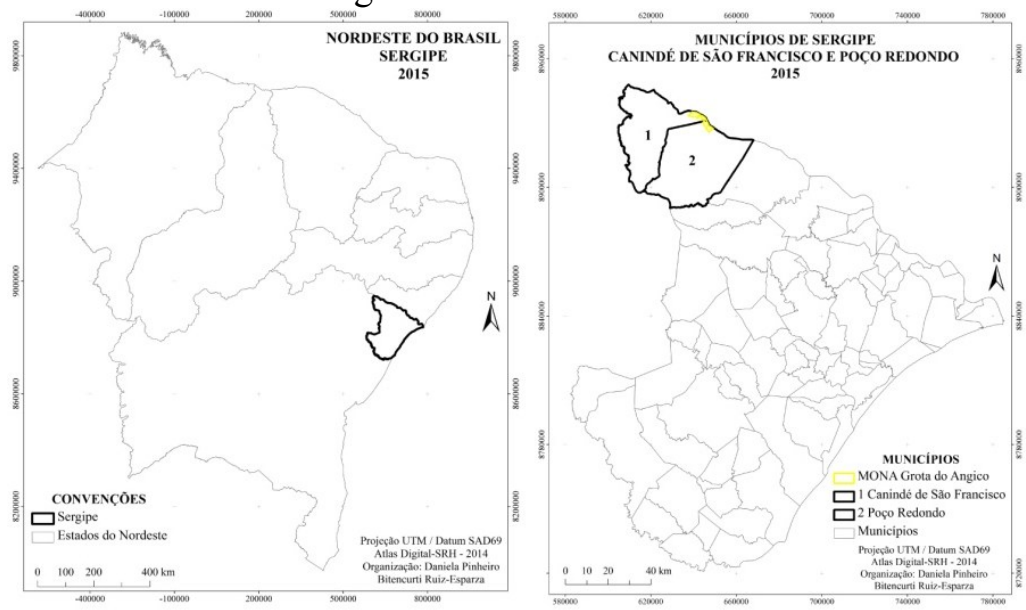

Figura 1: Localização da área de estudo. Fonte: Atlas SRH (2014).

A MONA Grota do Angico tem aproximadamente $21 \mathrm{~km}^{2} \mathrm{e}$ está localizada na divisa entre os dois municípios próxima ao rio São Francisco. É uma importante Unidade de Conservação de proteção integral do estado, classificada de acordo com a Lei 9985 de 18 de julho de 2000 (Brasil, 2000). 
BITENCOURT, D.P et all. Análise multitemporal do desmatamento nos...

Os dois municípios são cobertos exclusivamente pelo bioma Caatinga. A área tem aproximadamente $2.160 \mathrm{~km}^{2}$. É coberta pela cena 215-67 do satélite Landsat 5.

O relevo da área de estudo varia desde altitudes menores que $50 \mathrm{~m}$ até áreas que atingem mais de 650 metros, como mostram os três perfis aleatórios distribuídos sobre as imagens SRTM - Shuttle Radar Topography Mission (EMBRAPA, 2010). (Figura 2).

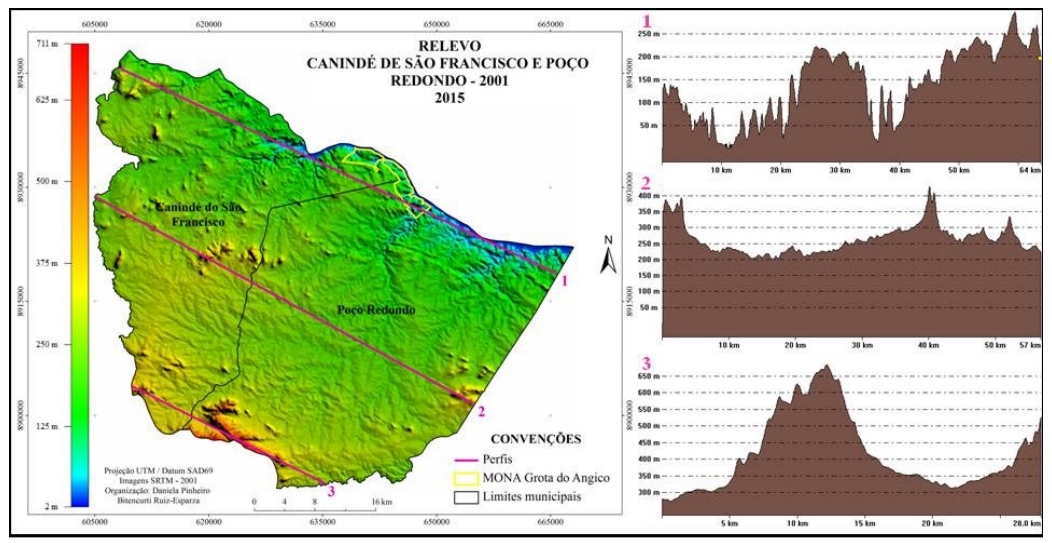

Figura 2: Relevo da área de estudo mostrando três perfis de altitude. Fonte: Modificado de EMBRAPA (2010).

A área apresenta-se como um pediplano caracterizado por relevo monótono, suave-ondulado, com vales estreitos e vertentes dissecadas. As altitudes variam de 20 a $500 \mathrm{~m}$ e com elevações residuais com altitudes de 500 a 800m (SEMARH, 2011).

\section{Coleta das imagens}

As imagens utilizadas foram coletadas pelo sistema Landsat 5 através do sensor TM. Foram selecionadas através dos arquivos da Divisão de Geração de Imagens (DGI, 2010) do INPE (Instituto Nacional de Pesquisas Espaciais) de Cachoeira Paulista referentes às décadas de 1980, 1990 e 2000. As características principais para 
BITENCOURT, D.P et all. Análise multitemporal do desmatamento nos...

seleção foram: cobertura mínima de nuvens e melhor visibilidade, além de uma adequada qualidade radiométrica.

As três cenas utilizadas foram: 215-67, 01/11/1987; 215-67, $17 / 10 / 1999$ e $215-67,07 / 12 / 2006$.

Tratamento das imagens - registro

O registro das imagens foi realizado através do software SPRING 5.2.4 - Sistema de Processamento de Imagens e Informações Georreferenciadas - desenvolvido pelo INPE (Câmara et al. 2005). As imagens foram registradas para o sistema de coordenadas UTM (Universal Transversor de Mercator) pelo datum SAD69 (South American Datum 1969) utilizando uma correção geométrica imagem-imagem, com polinômios de primeiro grau e interpolação do vizinho mais próximo (Arquivo/Registro/Tela/Imagem/Diretório/Selecionar/Fechar/Nom e/Criar/Salvar). É conveniente ressaltar que a resolução espacial e área das imagens de entrada são de $(30$ x 30$)$ metros. $\mathrm{O}$ registro teve como base uma imagem Landsat mais antiga, baixada gratuitamente do acerco georreferenciado de alta precisão da NASA (National Aeronautics and Space Administration) (NASA, 2010). Estas imagens permitem o registro confiável já que as duas imagens possuem mesma resolução espacial, são do mesmo sensor e representam a mesma área.

\section{Trabalho de campo}

As visitas a campo foram realizadas para coletar pontos de controle referentes as classes de Caatinga e as regiões de pasto da área. Os pontos de controle foram registrados através do receptor GPS (Geographic Positioning System) Gpsmap 64, com projeção UTM, Datum SAD69, e foram fotografados todos os pontos vistoriados.

A coleta dos pontos foi feita em fragmentos representativos e o mais homogêneo possível para cada classe de Caatinga.

Todos os pontos coletados em campo foram identificados no laboratório, através das fotografias e das imagens de satélite, 
BITENCOURT, D.P et all. Análise multitemporal do desmatamento nos...

juntamente com um especialista em botânica para a classificação dos mesmos. As classes geradas foram: Caatinga arbórea, incluindo mata ciliar com árvores altas e fragmentos de vegetação com árvores altas e próximas a cursos d'água; Caatinga arbóreaarbustiva, incluindo árvores de porte médio com dossel fechado, árvores de porte médio com dossel semiaberto e árvores de porte médio mescladas com arbustos; Caatinga arbustiva, incluindo arbustos verdes e arbustos secos com porte médio e baixo; Pasto, incluindo áreas abertas com pastagem verde, pastagem seca, agricultura, solo exposto e lajedo (Figura 3).

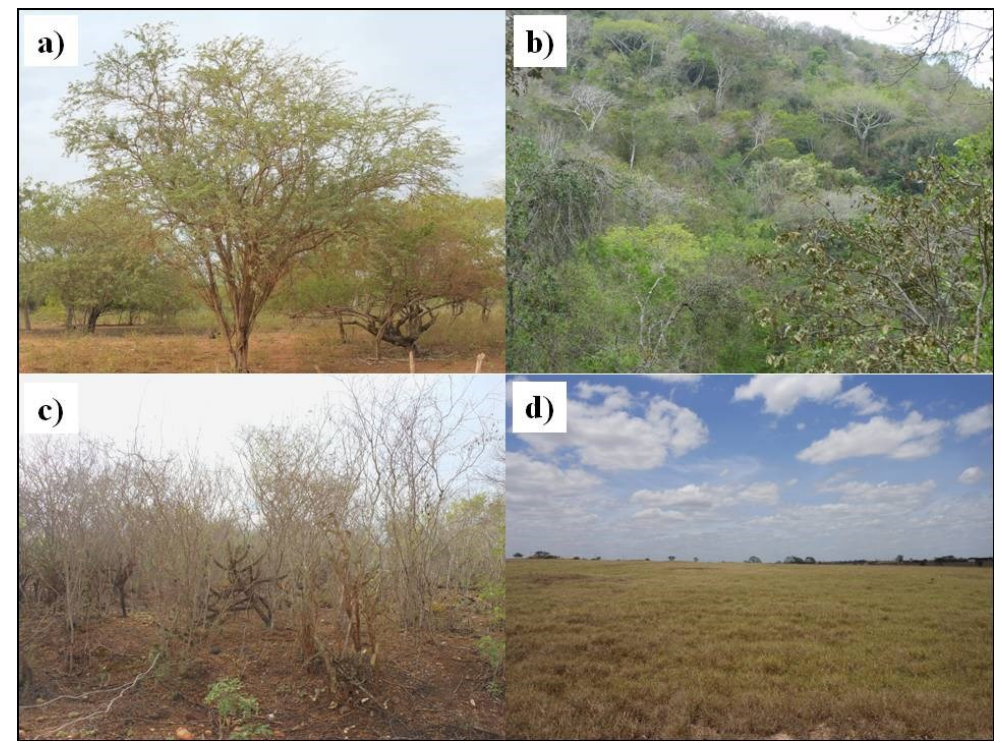

Figura 3: Classes de vegetação: a) Caatinga arbórea, b) Caatinga arbórea arbustiva, c) Caatinga arbustiva e d) Pasto.

\section{Análise Multitemporal}

Operações Aritméticas entre imagens

O processamento digital permite operações aritméticas entre imagens (INPE, 2010). As mais importantes são: adição; subtração; 
BITENCOURT, D.P et all. Análise multitemporal do desmatamento nos...

multiplicação; e divisão (razão espectral). As operações aritméticas são utilizadas em análises multiespectrais (diferentes canais espectrais de uma mesma cena) e em análises multitemporais (a mesma imagem em diferentes datas). As operações são efetuadas entre os níveis de cinza dos pixels correspondentes nas diversas imagens. A condição básica para estas operações é que as imagens estejam registradas, ou seja, georreferenciadas, para que haja uma perfeita superposição de pixels correspondentes (IBGE, 2001).

As operações aritméticas visam: a) redução da dimensionalidade dos dados que é obtida através das técnicas de compressão; b) ao realce das similaridades (adição e multiplicação); ou c) ao realce das diferenças (subtração e divisão) (INPE, 2010).

A razão entre duas bandas espectrais gera o Índice de Vegetação (IV), que se refere às medidas quantitativas, baseadas nos valores digitais, que tentam medir biomassa ou vigor vegetativo. Esta nova imagem de IV foi gerada no software SPRING 5.2.4, através da aplicação da subtração de bandas (B4 B3), para identificação de diferentes tipos de cobertura vegetal (Imagem/Operações Aritméticas/(A-B)/Executar). Um índice de vegetação com alto valor de brilho indica pixels cobertos por uma alta proporção de vegetação viva (Santos et al., 2010).

A Análise por Componentes Principais (ACP), também foi utilizada para gerar novas imagens que podem ser empregadas no estudo multitemporal da dinâmica da paisagem, gerando imagens dos parâmetros brilho e verdor a partir da primeira e da segunda componentes principais, respectivamente (Jesus \& Epiphanio, 2010). É uma técnica de transformação linear que é utilizada com diferentes propósitos: realce de bandas, decorrelação de bandas, classificações, compressões de dados, simulação de bandas pancromáticas, até detecção de mudanças. Estas análises e gerações de novas imagens foram realizadas no SPRING 5.2.4, utilizando as bandas 3,4 e 5 do satélite Landsat 5 (Imagem/Componentes Principais/Adquirir/Executar). 
BITENCOURT, D.P et all. Análise multitemporal do desmatamento nos...

\section{Interpretação visual}

Nesta etapa de fotointerpretação visual, realizada no SPRING 5.2.4, utilizamos elementos de reconhecimento, os quais servem de fatores-guia no processo de reconhecimento $\mathrm{e}$ identificação dos alvos na superfície terrestre através de uma fotografia aérea ou imagem de satélite. Estes elementos básicos de leitura de uma fotografia ou imagem são os seguintes: tonalidade e cor; forma e tamanho; padrão; textura; associação e sombra (Moreira, 2011). Estes elementos foram utilizados para auxiliar na identificação das diferenças entre as classes definidas para o trabalho.

Foi utilizada a chave de interpretação (Tabela 1) de objetos e feições representadas em imagens LANDSAT, 3(B), 4(G) e 5(R), que serviu como subsídio para a análise dos elementos de interpretação (Florenzano, 2011).

Tabela 1: Chave de Interpretação.

\begin{tabular}{lllll}
\hline \begin{tabular}{c} 
Classes de Uso da \\
\multicolumn{1}{c}{$\begin{array}{c}\text { Terra e } \\
\text { Cobertura } \\
\text { Vegetal }\end{array}$}
\end{tabular} & Tonalidade & Cor & Textura & Forma \\
\hline $\begin{array}{l}\text { Caatinga arbórea } \\
\text { Caatinga arbórea } \\
\text { arbustiva }\end{array}$ & & Verde & Rugosa & Irregular \\
\cline { 2 - 5 } Caatinga arbustiva & & Verde escuro & Rugosa & Irregular \\
\cline { 2 - 5 } Pasto & Verde claro & Rugosa & Irregular \\
\cline { 2 - 4 } Corpos d'água & Rosa / marrom & Lisa & Irregular \\
& & Azul escuro & Lisa & Irregular
\end{tabular}

\section{Classificação}

O método utilizado foi o de classificação por distância euclidiana, realizado no Software SPRING 5.2.4. É um procedimento de classificação supervisionada que utiliza esta distância para associar 
BITENCOURT, D.P et all. Análise multitemporal do desmatamento nos...

um pixel a uma determinada classe (INPE, 2010). O primeiro passo em um processo de classificação multiespectral é o treinamento. Treinamento é o reconhecimento da assinatura espectral das classes. Os campos de treinamento foram coletados e os polígonos foram gerados para todas as classes em análise, a partir dos dados coletados em campo. Utilizou-se da interpretação visual para identificação de padrões espectrais onde estas áreas devem representar áreas homogêneas das classes de interesse. A classificação foi e foram utilizadas as bandas originais, assim como as novas bandas geradas de cada cena. Foram utilizadas seis bandas para a classificação: as bandas originais, 3, 4 e 5, o IV, a ACP1 e a banda 5 com correção radiométrica (Imagem/Classificação/Criar/Campos de Treinamento/Nome/Criar/Adquirir/Salvar/Classificação/Dist.

Euclidiana/Analisar Amostras/Nome/Executar).

\section{Pós-classificação}

A pós-classificação é realizada sobre uma imagem classificada, com o objetivo de uniformizar os temas, ou seja, eliminar pontos isolados, classificados diferentemente de sua vizinhança (INPE, 2015. O resultado é uma imagem classificada com aparência menos ruidosa. As pós-classificações foram geradas no SPRING 5.2.4, onde, após testes e comparações, utilizamos peso 3 e limiar 3 (Imagem/Classificação/Pós-Classificação/Executar).

\section{Edição}

Uma vez realizada a classificação das imagens, torna-se necessário fazer uma pré-auditoria do mapeamento resultante (Câmara et al. 2006). Essa etapa é denominada de "edição", que teve por base a fotointerpretação, para a análise minuciosa (diretamente na tela do computador tendo como plano de fundo, para comparabilidade, a imagem original em composição colorida) dos polígonos temáticos gerados pela classificação. Os polígonos mapeados são aceitos ou reclassificados em outras classes, baseado na experiência do fotointérprete, que avalia padrões e aspectos de contexto. As análises foram feitas no SPRING 5.2.4. As cenas 
BITENCOURT, D.P et all. Análise multitemporal do desmatamento nos...

registradas obtiveram erros menores que meio pixel, ou seja, menor que 15 metros.

\section{Resultados e discussão}

O processo de desmatamento do bioma Caatinga se configura como um grave problema ambiental na região nordeste do Brasil, comprometendo assim toda biodiversidade presente nesta porção do território.

No estado de Sergipe a realidade apresenta-se de forma similar ao contexto nacional, onde os espaços outrora dominados pelas fisionomias de Caatinga arbórea perdem espaço cada vez mais para as áreas de pastagens, aumentando a suscetibilidade à erosão dos solos frente a ausência de cobertura vegetal (Ab'Saber, 1977).

Portanto, o resultado do presente estudo para as classificações do uso do solo para as décadas de 1980, 1990 e 2000, correspondem respectivamente as Figuras 4, 5 e 6.

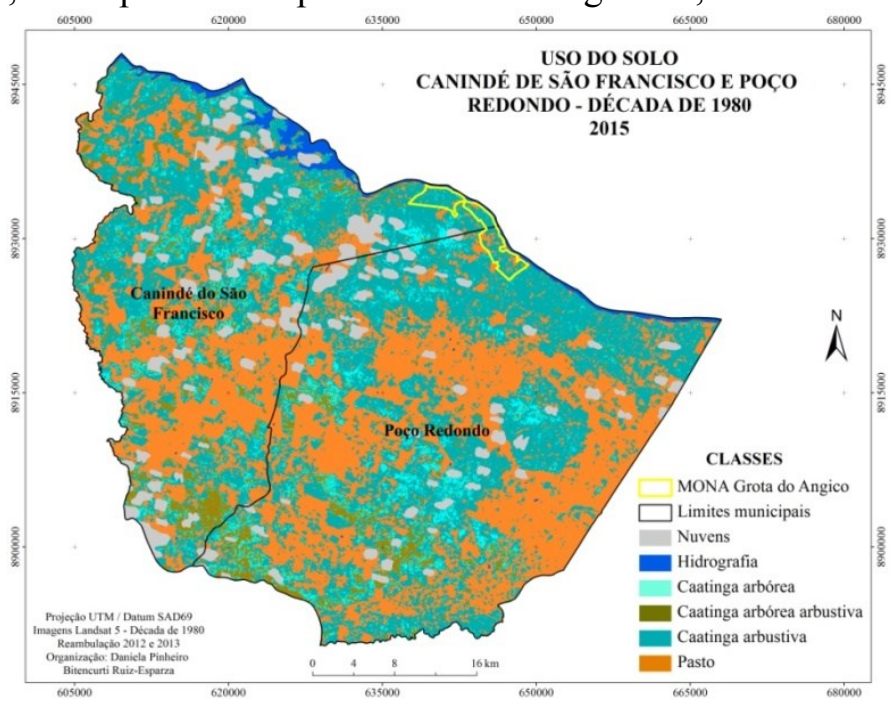

Figura 4: Mapa de uso do solo da década de 1980 na área de estudo. 
BITENCOURT, D.P et all. Análise multitemporal do desmatamento nos...

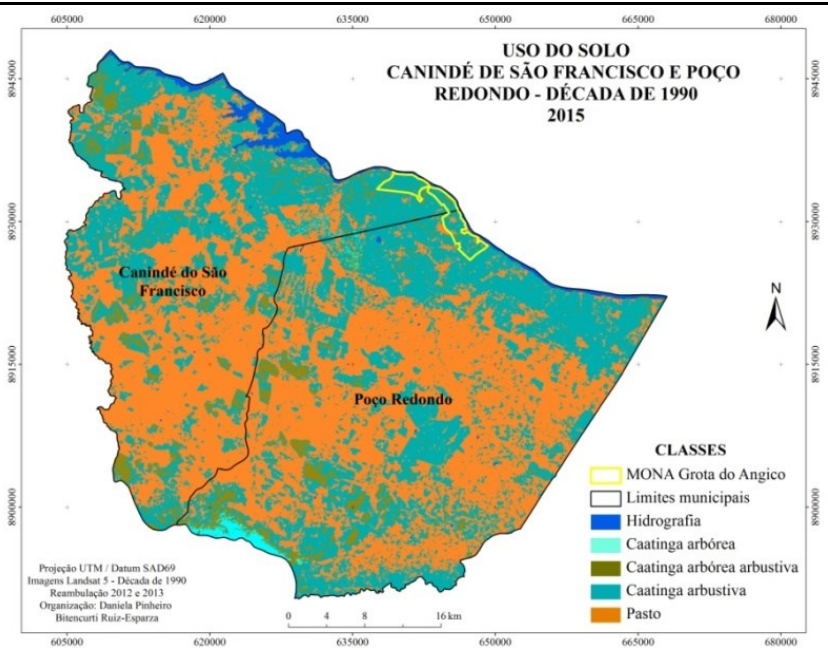

Figura 5: Mapa de uso do solo da década de 1990 na área de estudo.

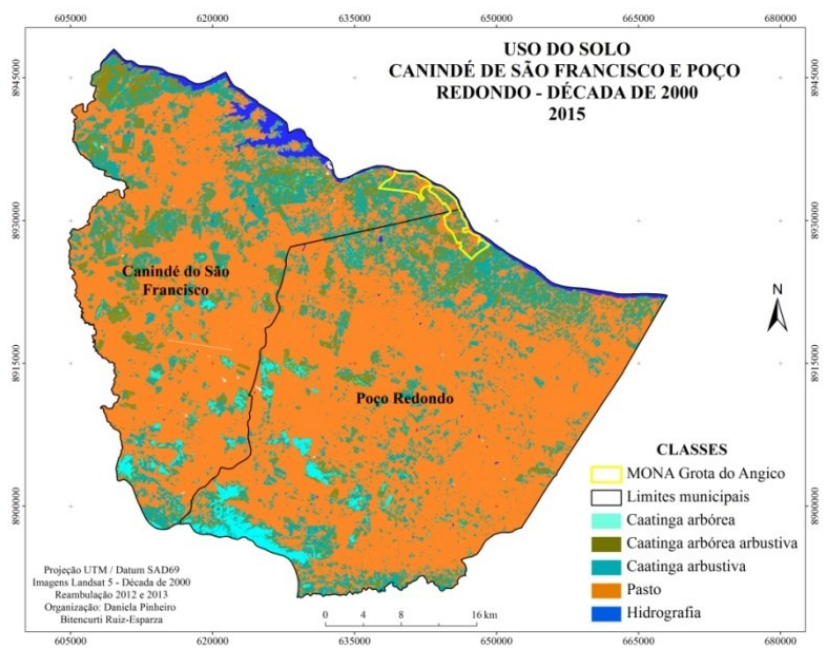

Figura 6: Mapa de uso do solo da década de 2000 na área de estudo. 
BITENCOURT, D.P et all. Análise multitemporal do desmatamento nos...

A tabela 1 mostra o cálculo das áreas classificadas assim como suas porcentagens em relação ao total classificado de cada década.

As classes totais para cada década apresentam uma diferença devido a passagem do satélite, onde o início e final de uma cena possuem pequenas variações.

Tabela 1: Total de áreas classificadas e porcentagens por década.

\begin{tabular}{lcccccc}
\hline $\begin{array}{c}\text { Classe de cobertura } \\
\text { do solo }\end{array}$ & \multicolumn{2}{c}{$\mathbf{1 9 8 0}$} & \multicolumn{2}{c}{$\mathbf{1 9 9 0}$} & \multicolumn{2}{c}{$\mathbf{2 0 0 0}$} \\
\hline & $\mathrm{Km}^{2}$ & $\%$ & $\mathrm{Km}^{2}$ & $\%$ & $\mathrm{Km}^{2}$ & $\%$ \\
Caatinga arbórea & 132,66 & 6,12 & 15,32 & 0,71 & 60,81 & 2,81 \\
Caatinga arbórea & 130,65 & 6,02 & 98,70 & 4,55 & 175,70 & 8,12 \\
arbustiva & 882,00 & 40,66 & 881,85 & 40,68 & 381,37 & 17,63 \\
Caatinga arbustiva & 834,18 & 38,46 & 1134,33 & 52,33 & 1506,74 & 69,65 \\
Pasto & 37,61 & 1,73 & 37,61 & 1,73 & 38,56 & 1,78 \\
Hidrografia & 151,92 & 7,00 & 0,00 & 0,00 & 0,00 & 0,00 \\
Nuvem & 2169,02 & 100,00 & 2167,80 & 100,00 & 2163,18 & 100,00 \\
& & & & & &
\end{tabular}

Portanto, para as três classificações referentes as três décadas, podemos observar o decréscimo dos fragmentos de Caatinga arbórea e Caatinga arbustiva, assim como o grande aumento das áreas de pasto. A Caatinga arbórea arbustiva foi a única classe que apresentou um aumento em relação a sua área.

A década de 1990 teve uma pequena diferença em relação as porcentagens das classes da Caatinga arbórea e Caatinga arbórea arbustiva, diminuindo nesta década em relação a década de 1980 e voltando a aumentar na década de 2000. Isto ocorre devido a resolução espectral das bandas originais que tem influência direta na classificação. Esta resposta espectral se refere as cores das imagens, ou seja, as cores geradas a partir das combinação das três bandas utilizadas para fazer a composição colorida. Neste trabalho utilizamos as bandas 3, 4 e 5 . 
BITENCOURT, D.P et all. Análise multitemporal do desmatamento nos...

Devemos levar em consideração principalmente os valores entre as décadas de 1980 e 2000 para estas classes, onde pode-se observar a compressão da vegetação e sua substituição por áreas de pastagens. Quando analisados os dados por município, apresentam as mesmas tendências (Figura 7).

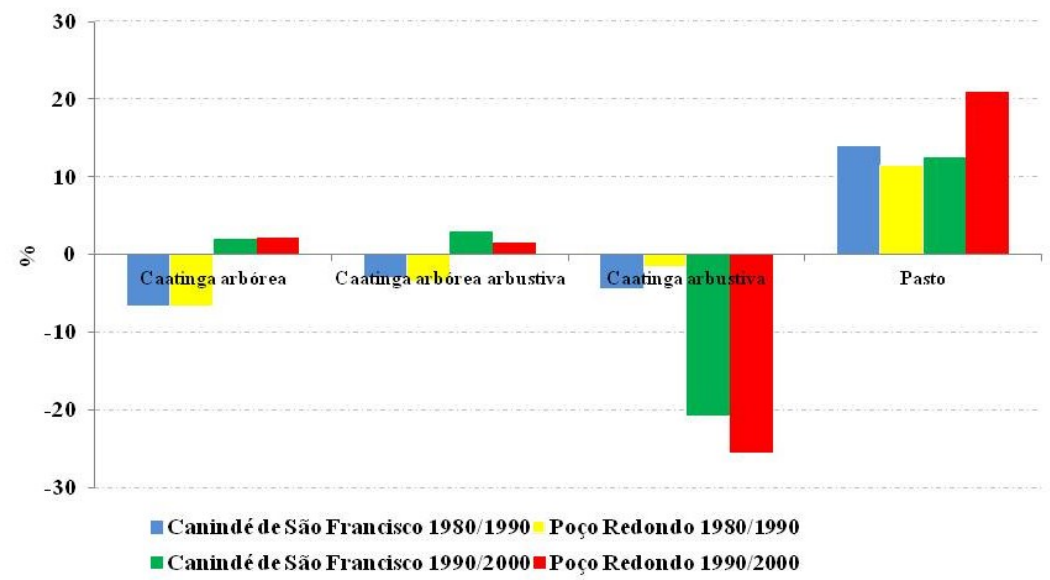

Figura : Porcentagem de aumento ou redução da cobertura das diferentes classes amostradas, nos municípios de Canindé de São Francisco e Poço Redondo entre as décadas de 1980, 1900 e 2000.

No que diz respeito especificamente a área da MONA Grota do Angico, apesar de apresentar aumentos significativos nas classes de Caatinga arbórea-arbustiva, houve uma grande diminuição na Caatinga arbustiva e consequente aumento das áreas de pastagens (Figura 8). 
BITENCOURT, D.P et all. Análise multitemporal do desmatamento nos...

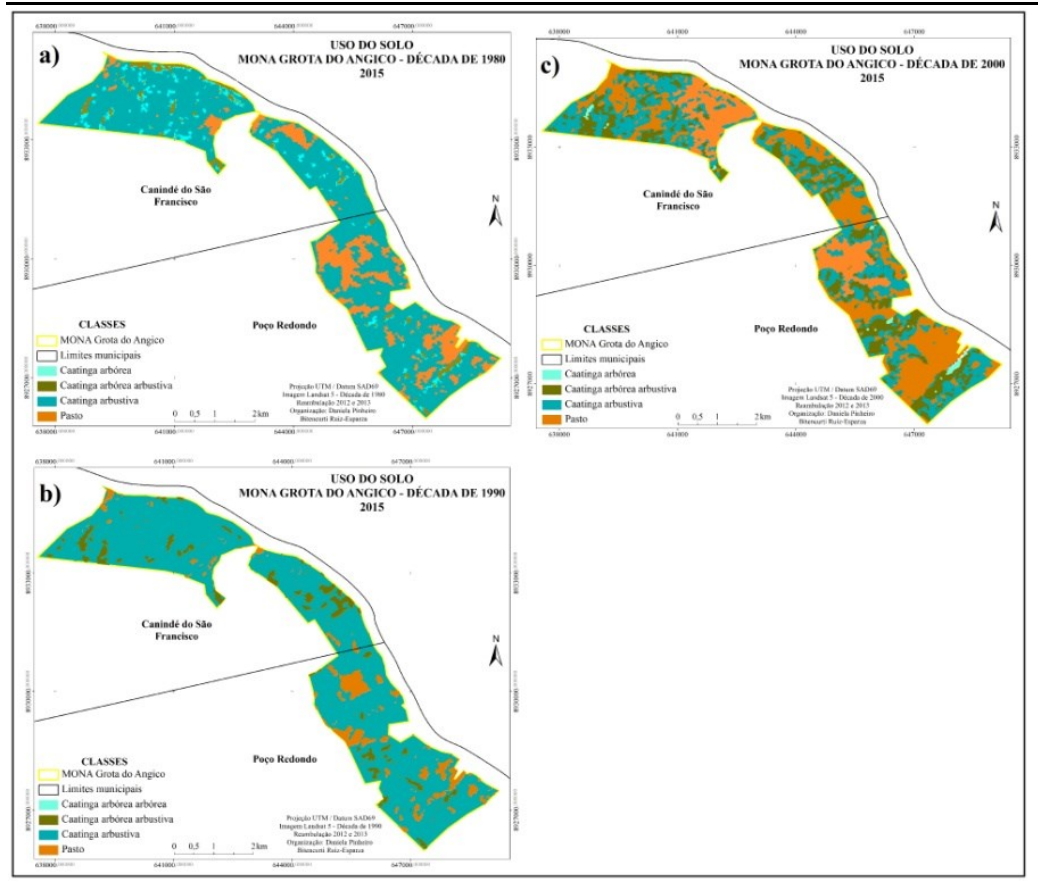

Figura 8: Mapa de cobertura do solo para o MONA Grota do Angico; a) Década de 1980, b) Década de 1990, c) Década de 2000.

No que concerne às décadas de 1980 e 1990, as classes de cobertura do solo Caatinga arbórea e pasto diminuíram, já nas décadas de 1990 e 2000 a única classe que diminuiu foi a Caatinga arbustiva (Tabela 2).

Pode-se destacar que os principais vetores que acarretam na supressão da vegetação da Caatinga são o processo de derrubada da Caatinga para dar espaço às pastagens e a utilização do carvão (Figura 8), como uma das fontes energéticas dominantes nas áreas rurais dos municípios, panorama similar ao encontrado no contexto nacional (HAUFF, 2010). 
BITENCOURT, D.P et all. Análise multitemporal do desmatamento nos...

Tabela 2: Total de áreas classificadas e porcentagens por década para o MONA Grota do Angico.

\begin{tabular}{lcccccc}
\hline $\begin{array}{c}\text { MONA Angico } \\
\text { Classe de } \\
\text { cobertura do solo }\end{array}$ & \multicolumn{2}{c}{$\mathbf{1 9 8 0}$} & \multicolumn{2}{c}{$\mathbf{1 9 9 0}$} & \multicolumn{2}{c}{$\mathbf{2 0 0 0}$} \\
\hline & $\mathrm{Km}^{2}$ & $\%$ & $\mathrm{Km}^{2}$ & $\%$ & $\mathrm{Km}^{2}$ & $\%$ \\
Caatinga arbórea & 0,95 & 4,54 & 0,00 & 0,00 & 0,19 & 0,91 \\
$\begin{array}{l}\text { Caatinga arbórea } \\
\text { arbustiva }\end{array}$ & 0,90 & 4,29 & 1,28 & 6,09 & 4,17 & 19,68 \\
$\begin{array}{l}\text { Caatinga } \\
\text { arbustiva }\end{array}$ & 15,81 & 75,24 & 18,12 & 86,23 & 7,61 & 35,92 \\
Pasto & 3,35 & 15,93 & 1,61 & 7,68 & 9,21 & 43,49 \\
Total & 21,02 & 100,00 & 21,02 & 100,00 & 21,17 & 100,00 \\
\hline
\end{tabular}

Assim, seguindo a lógica verificada no contexto dos municípios estudados, na análise temporal da Caatinga no MONA Grota do Angico, as três classes de Caatinga sofreram um decréscimo ao longo das décadas, sobretudo ocasionando o aumento significativo da classe pasto. Justifica-se, portanto a criação do espaço territorialmente protegido, tendo em vista a manutenção da biodiversidade da Caatinga nesses municípios.

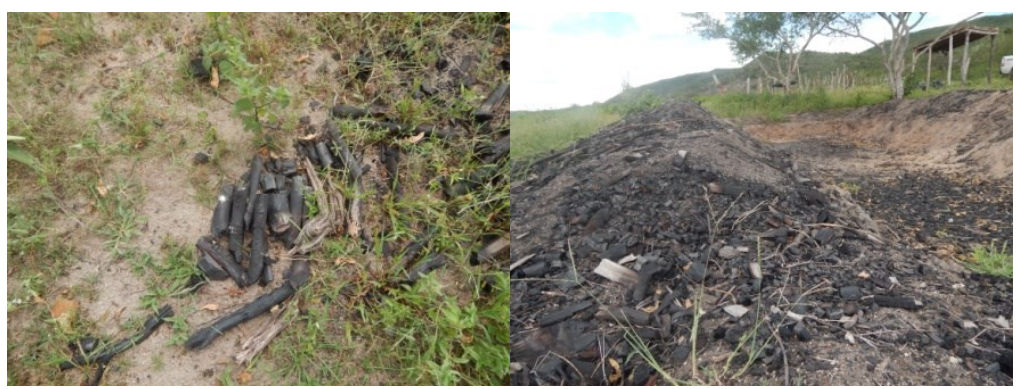

Figura 8: Produção de carvão vegetal em área de caatinga no município de Poço Redondo-Sergipe. 
BITENCOURT, D.P et all. Análise multitemporal do desmatamento nos...

\section{Conclusões}

A abordagem multitemporal nos proporciona ferramentas eficazes para o monitoramento do desmatamento através da delimitação, localização e quantificação das áreas degradadas ao longo do tempo.

Mesmo com algumas dificuldades em relação à resposta espectral, quando se trata de alvos semelhantes, como tipos de vegetação, a diferença no comportamento espectral de dois ou mais tipos de vegetação pode não ser tão marcante a ponto de ser percebida em imagens de satélites (Moreira, 2011). Encontramos este tipo de dificuldade principalmente nas classes de Caatinga, onde as feições são muito parecidas, entretanto, conseguimos obter uma discriminação aceitável das três categorias de Caatinga (arbórea, arbórea-arbustiva e arbustiva) propostas no trabalho.

Recomenda-se também a análise dos dados pluviométricos, através da obtenção das médias mensais pluviométricas da área de estudo, os quais se tornariam imprescindíveis para uma escolha correta das imagens de satélite já que a resposta espectral da vegetação tem grande variabilidade com a presença de água (MCT, 2011).

Ademais, pode-se salientar a contribuição da análise multitemporal no monitoramento da dinâmica fitogeográfica da Caatinga, subsidiando assim análises que possam embasar ações de conservação nesse bioma rico em biodiversidade, porém muito devastado.

\section{Referências bibliográficas}

AB'SABER, A.N. O domínio morfoclimático semiárido das Caatingas brasileiras. Geomorfologia. 1974. pp. 1-39.

ASSOCIAÇÃO CAATINGA. CAATINGA: um bioma exclusivamente brasileiro. 2012. Disponível em: 
BITENCOURT, D.P et all. Análise multitemporal do desmatamento nos...

http://www.acaatinga.org.br/index.php/o-bioma/sobre-obioma/caracterizacao/. Acesso em: 6 de ago. de 2012.

BRANDÃO JR., A. \& SOUZA JR. C. Mapping unofficial roads with Landsat images: a new tool to improve the monitoring of the Brazilian Amazon rainforest. International Journal of Remote Sensing. 2006. v27, 1, 177-189.

CÂMARA, G.; VALERIANO, D.M.; SOARES, J.V. Metodologia para o Cálculo da Taxa Anual de Desflorestamento na Amazônia Legal. São José dos Campos: Instituto Nacional de Pesquisas Espaciais, 2006. 24 p.

CÂMARA, G.; DAVIS, C.; MONTEIRO M.V. Introdução à Ciência da Geoinformação. São José dos Campos: INPE, 2005. Disponível em: http://www.dpi.inpe.br/gilberto/livro. Acesso em: 3 de abr. de 2011.

COUTURIER, S. Evaluación de la cobertura vegetal en México: aciertos y sesgos del mapa derivado del sensor MODIS. En Aplicaciones MODIS para el monitoreo del territorio. 2011. México.

DGI. Divisão de Geração de Imagens. INPE. 2010. Disponível em http://www.dgi.inpe.br. Acesso em: 4 de abr. de 2010.

EMBRAPA. Brasil em Relevo. Disponível em: http://www.relevobr.cnpm.embrapa.br/download/index.htm. Acesso em: 14 de mai de 2010.

GREEN, D.R. \& W. HARTLEY. Integrating photointerpretation and GIS for vegetation mapping: some issues of error. En: R. Alexander y A. C. Millington (eds.). Vegetation Mapping from Patch to Planet. John Wiley and Sons; Nueva York, 2000. pp. 103-134. 
BITENCOURT, D.P et all. Análise multitemporal do desmatamento nos...

HAUFF, S.N. Representatividade do Sistema Nacional de Unidades de Conservação na Caatinga. Brasília: Programa das Nações Unidas para o Desenvolvimento (PNUD). 2010.

IBGE - INSTITUTO BRASILEIRO DE GEOGRAFIA E ESTATÍSTICA. Introdução ao Processamento Digital de Imagens. Rio de Janeiro: IBGE, 2001.

IBGE - INSTITUTO BRASILEIRO DE GEOGRAFIA E ESTATÍSTICA. Mapa de biomas do Brasil. Escala 1:5.000.000. Rio de Janeiro: IBGE, 2004. Disponível em: http://www.ibge.gov.br/home/presidencia/noticias/21052004bioma s.shtm. Acesso em: 21 de mar. de 2011.

INSTITUTO NACIONAL DE PESQUISAS ESPACIAIS (INPE). Sistema de Processamento de Informações Georeferenciadas (SPRING) versão 5.2. São José dos Campos: Instituto Nacional de Pesquisas Espaciais, 2010. Disponível em: http://www.dpi.inpe.br/spring/portugues/index.html. Acesso em: 29 de abr. 2010.

JESUS, S. C.; EPIPHANIO, J.C.N. Sensoriamento remoto multissensores para a avaliação temporal da expansão agrícola municipal. Bragantia. 2010. vol.69, n.4, pp. 945-956.

MARTINS SOUZA FILHO, P.W., PARADELLA, W.R., SOUZA JR., C., VALERIANO, D. de M., \& MIRANDA, F.P. Sensoriamento remoto e recursos naturais da Amazônia. Revista Ciência e Cultura da SBPC. 2006. 58(3), 37-41.

MCT - MINISTÉRIO DE CIÊNCIA E TECNOLOGIA. Desertificação e mudanças climáticas no semiárido brasileiro. Campina Grande, PB. 2011. Insa-PB. 
BITENCOURT, D.P et all. Análise multitemporal do desmatamento nos...

MOREIRA, M.A. Fundamentos do Sensoriamento Remoto e metodologias de aplicação. 4. ed. atual. ampli. - Viçosa, MG: Ed. UFV, 2011. 422p.

NASA- NATIONAL AERONAUTICS AND SPACE ADMINISTRATION. Imagens Landsat. 2010. Disponível em: ftp://ftp.glcf.umiacs.umd.edu/. Acesso em : 19 de ago de 2010.

NOVO, E.M.L. de M. Sensoriamento Remoto: Princípios e Aplicações. $4^{a}$ edição. São Paulo: Editora Edgard Blücher Ltda. 2011.

SANTOS, A.R.; PELUZIO, T.M.O.; SAITO, N.S. SPRING 5.1.2. Aplicações e práticas. Mundo da Geomática. Alegre: CAUFES, 2010.153p.

SEMARH. Secretaria de Estado do Meio Ambiente e dos Recursos Hídricos de Sergipe. Plano de Manejo do Monumento Natural Grota do Angico. 2011. 55p.

SISCOM/IBAMA. Sistema Compartilhado de Informações Ambientais. Monitoramento da Caatinga. 2010. Disponível em: http://siscom.ibama.gov.br/monitorabiomas/caatinga/caatinga.htm. Acesso em: 18 de set. de 2011

Recebido em outubro de 2015

Aceito em agosto de 2016 
BITENCOURT, D.P et all. Análise multitemporal do desmatamento nos... 